\title{
Um novo registro de Trachycephalus mambaiensis (Amphibia, Anura, Hylidae), no Estado de Minas Gerais, Brasil
}

\author{
Adriano Lima Silveira ${ }^{1^{*}}$ \\ Sandro Aparecido Pacheco ${ }^{2}$ \\ ${ }^{1}$ Setor de Herpetologia, Departamento de Vertebrados \\ Museu Nacional, Universidade Federal do Rio de Janeiro \\ Quinta da Boa Vista, São Cristóvão, CEP 20940-040, Rio de Janeiro - RJ, Brasil \\ ${ }^{2}$ Rua Orestes Moura, 285, Papagaio, CEP 38770-000, João Pinheiro - MG, Brasil \\ *Autor para correspondência \\ biosilveira@yahoo.com.br
}

\section{Resumo}

Trachycephalus mambaiensis foi recentemente descrita de duas localidades no Estado de Goiás, no Brasil central. Apresenta-se aqui um novo registro de T. mambaiensis, o qual constitui o primeiro registro no Estado de Minas Gerais, Brasil. A espécie foi encontrada em três localidades no Município de João Pinheiro, uma área de Cerrado no noroeste de Minas Gerais. Trachycephalus mambaiensis é considerada uma espécie endêmica do bioma Cerrado.

Palavras-chave: Cerrado, Distribuição geográfica, Hylidae, Minas Gerais, Trachycephalus mambaiensis

\section{Abstract}

A new record of Trachycephalus mambaiensis (Amphibia, Anura, Hylidae), in the State of Minas Gerais, Brazil. Trachycephalus mambaiensis was recently described from two localities in the State of Goiás, in central Brazil. In this paper a new record of T. mambaiensis is presented, which is the first one in the State of Minas Gerais, Brazil. The species was found in three localities in the Municipality of João Pinheiro, a Cerrado area in northwest Minas Gerais. Trachycephalus mambaiensis is considered an endemic species of the Cerrado biome.

Key words: Cerrado, Geographic distribution, Hylidae, Minas Gerais, Trachycephalus mambaiensis

O gênero Trachycephalus Tschudi, 1838 (Hylidae, Hylinae) compreende atualmente 12 espécies distribuídas das áreas baixas do México, ao longo da América Central, América do Sul a leste dos Andes, até o norte da Argentina e sul do Brasil, das quais dez espécies ocorrem em território brasileiro (FAIVOVICH et al., 2005; KWET; SOLÉ, 2008; FROST, 2011). Trachycephalus mambaiensis Cintra, Silva, Silva Jr., Garcia e Zaher, 2009 foi descrita recentemente de duas localidades no bioma Cerrado, no Estado de Goiás, Brasil central (municípios de Mambaí e São Domingos) (CINTRA et al., 2009). Além de T. mambaiensis, duas outras espécies do gênero são registradas no Cerrado: T. nigromaculatus Tschudi, 1838 e T. venulosus (Laurenti, 1768) (COLLI 
et al., 2002; FROST, 2011). No presente trabalho é apresentado um novo registro de T. mambaiensis, o qual constitui o primeiro registro da espécie no Estado de Minas Gerais.

Durante amostragens de anfíbios entre 2001 e 2009, foram coletados três espécimes de T. mambaiensis no Município de João Pinheiro, uma área de Cerrado no noroeste de Minas Gerais. Os mesmos foram depositados na Coleção de Anfíbios do Museu Nacional/ Universidade Federal do Rio de Janeiro (MNRJ). Dois machos adultos foram coletados na Fazenda Gameleira (1740’39,62”S; 46 ${ }^{\circ} 11^{\prime} 09,36^{\prime}$ 'W; 725m altitude), em área alterada próxima a remanescentes de floresta estacional semidecidual. Um deles foi encontrado na sede da fazenda, em 15 de outubro de 2001 (MNRJ 38859), e o outro estava vocalizando à noite em uma lagoa temporária, em 14 de novembro de 2004 (MNRJ 38856; Figura 1). Nesta última ocasião, havia outro exemplar vocalizando, o qual não foi coletado. $\mathrm{O}$ terceiro espécime, uma fêmea juvenil (MNRJ 54644), foi coletado entre novembro de 2007 e abril de 2008, em uma área alterada de floresta de galeria na borda do Capão da Água Limpa (1744'25,54'S; 4609'49,03”'W; $802 \mathrm{~m}$ altitude). Esta localidade compreende uma pequena reserva natural com formações de floresta de galeria e cerrado sentido restrito na periferia da cidade de João Pinheiro, mas próxima a formações de floresta estacional semidecidual. Outra fêmea adulta foi encontrada e apenas fotografada (Figura 2), em janeiro de 2009, repousando no tronco de uma árvore em floresta de galeria à margem do rio Verde, na região da Bocaina

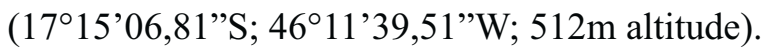

Os dois espécimes machos aqui registrados haviam sido identificados como T. nigromaculatus em um estudo sobre composição da fauna de anfíbios de João Pinheiro (SILVEIRA, 2006), antes da descrição de $T$. mambaiensis. Entretanto, esses machos e as duas fêmeas também procedentes de João Pinheiro apresentaram os caracteres diagnósticos de T. mambaiensis visíveis externamente, incluindo a ausência de crista occipital. Esta condição não é observada em T. nigromaculatus, a qual apresenta crista occipital (senso CINTRA et al., 2009).

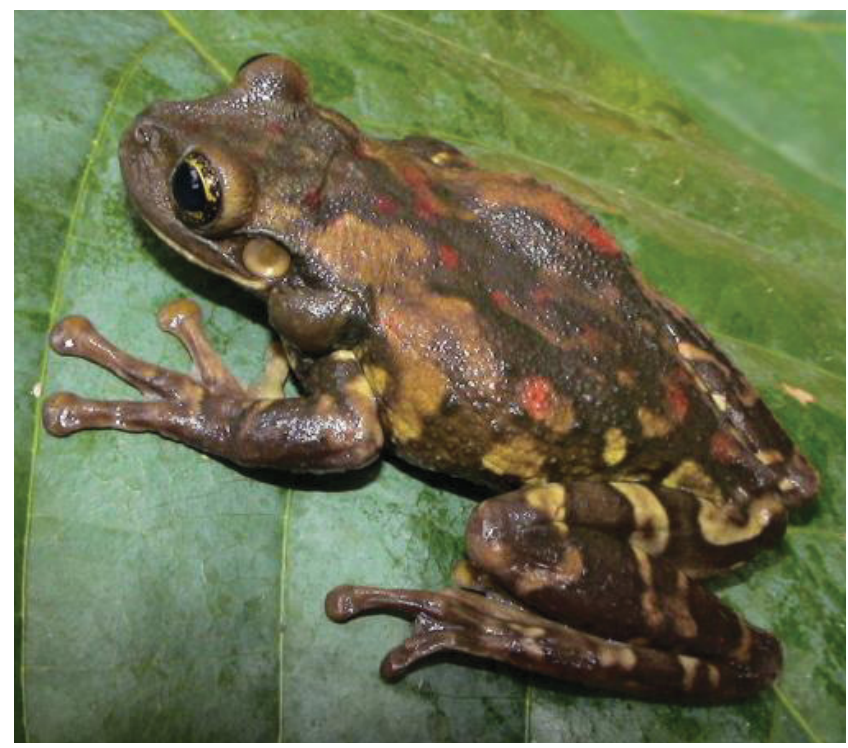

FIGURA 1: Macho adulto de Trachycephalus mambaiensis (MNRJ 38856) coletado na Fazenda Gameleira, Município de João Pinheiro, Minas Gerais.

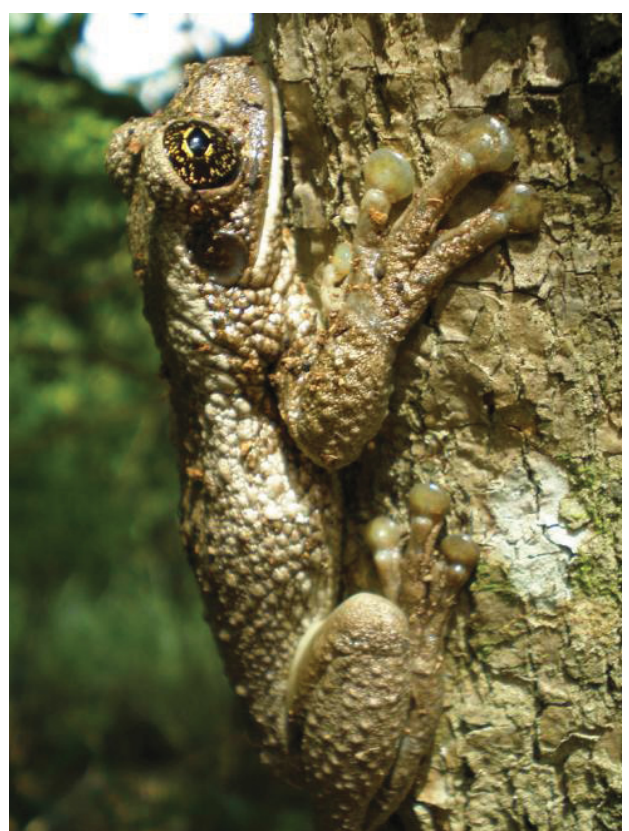

FIGURA 2: Fêmea adulta de Trachycephalus mambaiensis encontrada na margem do rio Verde, Bocaina, Município de João Pinheiro, Minas Gerais.

$\mathrm{O}$ registro de T. mambaiensis em João Pinheiro representa uma extensão da distribuição geográfica conhecida da espécie em cerca de $380 \mathrm{~km}$ a sul da localidade de registro prévio mais próxima (Goiás: Mambaí - localidade-tipo; CINTRA et al., 2009; Figura 3). Como as três áreas de registros conhecidos de T. mambaiensis estão inseridas na porção nuclear do Cerrado, a espécie é considerada endêmica do bioma. 


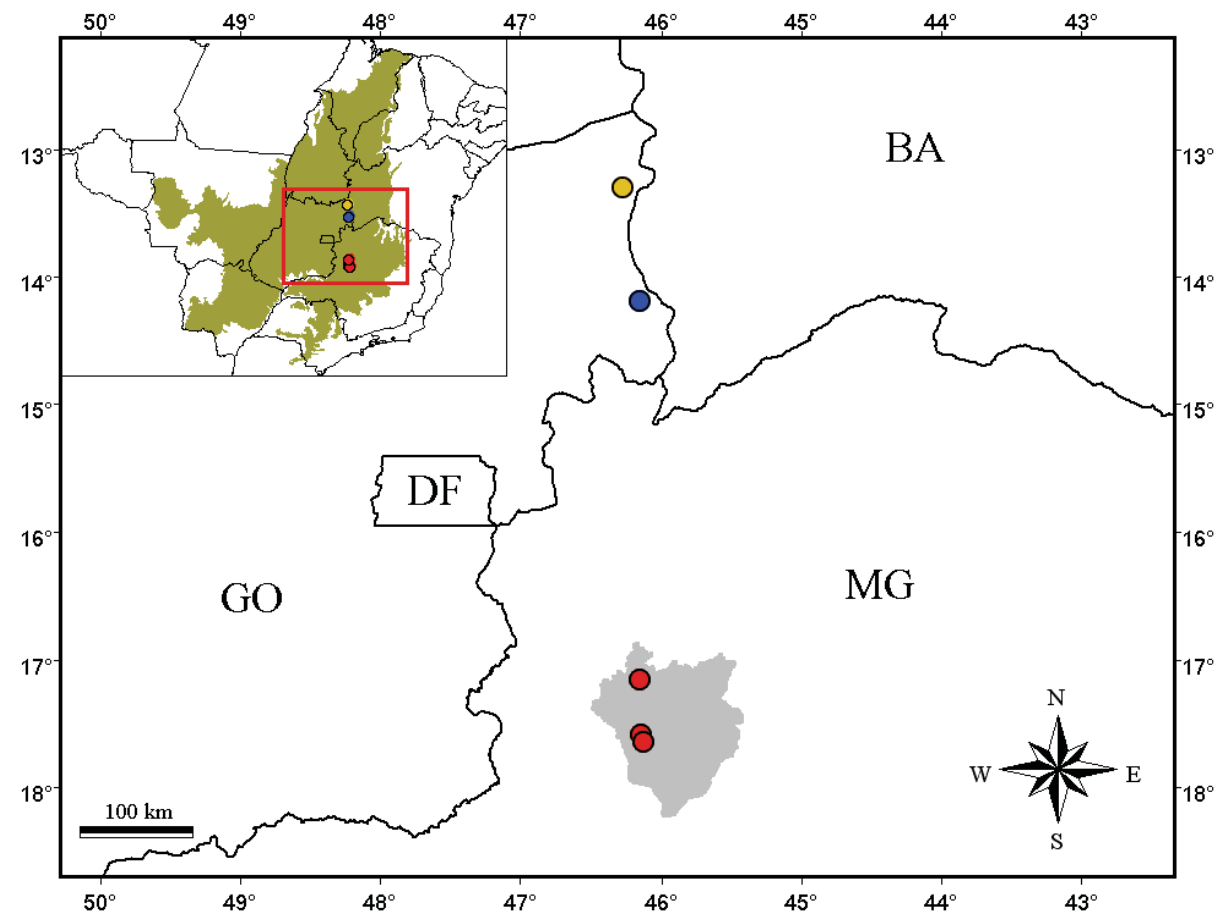

FIGURA 3: Distribuição geográfica de Trachycephalus mambaiensis: Mambaí, Goiás - localidade-tipo (círculo azul); São Domingos, Goiás (círculo amarelo) e João Pinheiro, MG - novo registro (círculos vermelhos). O bioma Cerrado destacado em verde e o Município de João Pinheiro destacado em cinza.

\section{Agradecimentos}

A Waldemar Luiz Barbosa, pelo auxílio nas coletas em campo.

\section{Referências}

CINTRA, C. E. D.; SILVA, H. L. R.; SILVA JR., N. J.; GARCIA, P. C. A.; ZAHER, H. A new species of Trachycephalus (Amphibia, Anura, Hylidae) from State of Goiás, Brazil. Zootaxa, Auckland, v. 1975, p. 58-68, 2009.

COLLI, G. R.; BASTOS, R. P.; ARAÚJO, A. F. B. The character and dynamics of the Cerrado herpetofauna. In: OLIVEIRA, P. S.; MARQUES, R. J. (Eds.). The Cerrados of Brazil: ecology and natural history of a Neotropical savanna. New York: Columbia University Press, 2002, p. 223-241.
FAIVOVICH, J.; HADDAD, C. F. B.; GARCIA, P. C. A.; FROST, D. R.; CAMPBELL, J. A.; WHEELER, W. C. Systematic review of the frog family Hylidae, with special reference to Hylinae: phylogenetic analysis and taxonomic revision. Bulletin of the American Museum of Natural History, New York, v. 294, p. $1-240,2005$.

FROST, D. Amphibian species of world 5.5, an online reference. 2011. New York, The American Museum of Natural History. Disponível em <http://research.amnh.org/herpetology/amphibia>. Acesso em: 05 de abril de 2011.

KWET A.; SOLÉ, M. A new species of Trachycephalus (Anura: Hylidae) from the Atlantic Rain Forest in southern Brasil. Zootaxa, Auckland, v. 1947, p. 53-67, 2008.

SILVEIRA, A. L. Anfíbios do município de João Pinheiro, uma área de Cerrado no noroeste de Minas Gerais. Arquivos do Museu Nacional, Rio de Janeiro, v. 64, n. 2, p. 131-139, 2006. 